\title{
TagSNP transferability and relative loss of variability prediction from HapMap to an admixed population Tulio C Lins ${ }^{\dagger}$, Breno S Abreu ${ }^{\dagger}$ and Rinaldo W Pereira*
}

\author{
Address: Programa de Pós-Graduação em Ciências Genômicas e Biotecnologia, Universidade Católica de Brasília, Brasília, DF, Brazil \\ Email: Tulio C Lins - lins.tulio@gmail.com; Breno S Abreu - brenoabreu@brenoabreu.com; Rinaldo W Pereira* - rinaldo@pos.ucb.br \\ * Corresponding author †Equal contributors
}

Published: 14 August 2009

Journal of Biomedical Science 2009, 16:73 doi:10.1 I86/1423-0I27-16-73

This article is available from: http://www.jbiomedsci.com/content//6/I/73

(C) 2009 Lins et al; licensee BioMed Central Ltd.

This is an Open Access article distributed under the terms of the Creative Commons Attribution License (http://creativecommons.org/licenses/by/2.0), which permits unrestricted use, distribution, and reproduction in any medium, provided the original work is properly cited.
Received: 23 June 2009

Accepted: 14 August 2009

\begin{abstract}
Background: The application of a subset of single nucleotide polymorphisms, the tagSNPs, can be useful in capturing untyped SNPs information in a genomic region. TagSNP transferability from the HapMap dataset to admixed populations is of uncertain value due population structure, admixture, drift and recombination effects. In this work an empirical dataset from a Brazilian admixed sample was evaluated against the HapMap population to measure tagSNP transferability and the relative loss of variability prediction.
\end{abstract}

Methods: The transferability study was carried out using SNPs dispersed over four genomic regions: the PTPN22, HMGCR, VDR and CETP genes. Variability coverage and the prediction accuracy for tagSNPs in the selected genomic regions of HapMap phase II were computed using a prediction accuracy algorithm. Transferability of tagSNPs and relative loss of prediction were evaluated according to the difference between the Brazilian sample and the pooled and single HapMap population estimates.

Results: Each population presented different levels of prediction per gene. On average, the Brazilian (BRA) sample displayed a lower power of prediction when compared to HapMap and the pooled sample. There was a relative loss of prediction for BRA when using single HapMap populations, but a pooled HapMap dataset generated minor loss of variability prediction and lower standard deviations, except at the VDR locus at which loss was minor using CEU tagSNPs.

Conclusion: Studies that involve tagSNP selection for an admixed population should not be generally correlated with any specific HapMap population and can be better represented with a pooled dataset in most cases.

\section{Background}

Since association studies were first introduced as a tool in understanding the genetic basis of complex phenotypes [1] an enormous methodological and analytical framework has been developed with regard to regions of high linkage disequilibrium (LD) and common haplotypes for genome-wide LD mapping [2,3]. The extension and local- ization of those regions are the mainstream in developing a set of SNPs capable of statistically representing untyped markers the tagSNPs reducing the costs of medium and high throughput genotyping in association studies [2-6]. The application of public genome data brought about great advances in the understanding of genetic variability and helped design association studies for complex pheno- 
types among several human populations of different ethnic backgrounds $[7,8]$. The three continental population samples in the HapMap project Utah residents with northern and western European ancestry (CEU), EastAsians (Japanese from Tokyo and Han Chinese from Beijing) (CHB+JPT) and African Yoruba from Ibadan, Nigeria (YRI) are used in experimental design as a reference for association studies in worldwide populations [6-9].

The challenge in establishing the HapMap as a standard for research is highlighted by the observation that the distribution of the haplotype blocks differs between population groups due to genetic and demographic effects [10]. However, tagSNP sharing from the HapMap dataset is commonly described as appropriately applied in European and East Asian populations [11-17], but less effective in other structured or multi-ethnic populations $[9,10,18,19]$. Such differences increase proportionally with the geographical distance between the HapMap data collection points and the actual sample collection $[6,9,15,17]$. Although the project never stated that these samples were representative of global variation, the fact that the HapMap study was carried out using only these ethno-geographic samples has been cited against the use of such data in populations that have a history of recent admixture [20-22].

Admixed populations can be useful in detecting genetic contributors to complex traits that differ in frequency between distinct populations. The admixture mapping approach has been proposed as an effective method for the identification of disease-susceptibility alleles with higher probability due to admixture-generated linkage disequilibrium extension [23]. Considering that the LatinAmerican people are one of the most heterogeneous around the world [24-26] as a result of mating primarily amongst three ethnic groups Europeans, Native (South) Americans and Africans the admixture mapping should be used as an alternative approach for the identification of disease-susceptibility loci $[21,27]$.

Therefore, unintended use of tagging SNP data in admixed populations could lead to spurious results since there is evidence that admixture impacts the linkage disequilibrium structure, affecting the association of SNPs with etiological factors $[28,29]$. Such issues could render HapMap-based tagSNP selection approaches for admixed populations inaccurate or even useless. Moreover, knowledge of the degree of portability of HapMap data to admixed populations is also needed in order to comprehend whether there is loss or gain of variability when using tagSNPs selected from the consortium populations. Thus, the aim of this work was to develop a first approach to evaluate the tagSNP transferability from HapMap to the
Brazilian admixed population, using 37 SNPs distributed between four loci: VDR, PTPN22, HMGCR and CETP.

\section{Methods \\ Population sample}

The sample of Brazilian subjects (BRA) consisted of 200 unrelated parents randomly selected from paternity test trios. A stratified sampling approach was adopted to represent the five Brazilian geopolitical regions according to each individual's place of birth. Genetic ancestry coefficients were estimated $[30,31]$ so as to validate the admixture source of the population. All sampled individuals signed an informed consent allowing the use of their DNA for paternity testing and further anonymous population genetics research.

The genotypes of the HapMap population samples were retrieved from the database (Data Rel 21a/phaseII Jan07, on NCBI B35 assembly, dbSNP b125) consisting of 89 unrelated East Asian individuals (CHB+JPT) comprising 45 Han Chinese from Beijing and 44 Japanese from Tokyo; 90 individuals of northern and western European origin (CEU); and 90 Yoruba individuals (YRI) from Ibadan, Nigeria. All HapMap population genotypes for each gene were combined into a pooled sample (POOL; $n$ $=269$ ) in order to test a representative multi-ethnic population thereby resulting in a final set of five population samples: CHB+JPT, CEU, YRI, POOL and BRA. The research project was approved by the Universidade Católica de Brasília Ethics Review Board.

\section{SNP selection and genotyping}

The SNP selection approach accounted for the markers that were polymorphic in at least one HapMap population and dispersed with average intervening distances of 5 $\mathrm{kb}[13,32]$. Data for the HapMap analyses were dumped directly from the website (Table 1). Genotyping in the Brazilian sample was performed using an optimized PCR reaction to co-amplify the fragments in distinct multiplex panels for each gene marker. Afterwards, the PCR-amplified products were purified by enzymatic treatment with exonuclease I (ExoI) and shrimp alkaline phosphatase (SAP) enzymes in order to eliminate non-incorporated dNTPs and primers. Finally, the minisequencing reaction was performed using the SNaPshot ${ }^{\circledR}$ Multiplex minisequencing kit reaction mix (Applied Biosystems) and the products of the SNaPshot ${ }^{\circledR}$ reaction were analyzed on the ABI 3100 Genetic Analyser (Applied Biosystems) using an ABI 3700 POP-6 ${ }^{\circ}$ polymer. Genotypes were called using GeneScan Analysis Software, version 3.7 (Applied Biosystems) and Genotyper version 3.7 (Applied Biosystems). An optimized multiplex single-base extension PCR was implemented according to a protocol described elsewhere [33]. 
Table I: Characteristics of genomic regions genotyped in this study

\begin{tabular}{|c|c|c|c|c|c|c|}
\hline SNP rs & Gene & Allele & Chr & Position & Average Distance $(\mathrm{Kb})$ & Gene Extension (Kb) \\
\hline rs3789607 & PTPN22 & $\mathrm{C} / \mathrm{T}$ & 1 & II4078476 & 5.80 & 34.80 \\
\hline rs 2476600 & PTPN22 & $\mathrm{A} / \mathrm{G}$ & 1 & 114081776 & & \\
\hline rs 1217395 & PTPN22 & $A / G$ & I & II4086477 & & \\
\hline rs247660I & PTPN22 & $\mathrm{A} / \mathrm{G}$ & I & $1 \mid 4089610$ & & \\
\hline rs2476602 & PTPN22 & $\mathrm{A} / \mathrm{G}$ & 1 & $1 \mid 4108997$ & & \\
\hline$r s 1217418$ & PTPN22 & $A / G$ & 1 & $1|4| 13273$ & & \\
\hline rs3931914 & HMGCR & $\mathrm{C} / \mathrm{G}$ & 5 & 74663770 & 4.08 & 28.52 \\
\hline rs3761740 & HMGCR & $\mathrm{A} / \mathrm{C}$ & 5 & 74667889 & & \\
\hline rs 10515198 & HMGCR & $\mathrm{C} / \mathrm{T}$ & 5 & 74677316 & & \\
\hline rs224|402 & HMGCR & $\mathrm{A} / \mathrm{T}$ & 5 & 74682011 & & \\
\hline rs 12654264 & HMGCR & $\mathrm{A} / \mathrm{T}$ & 5 & 74684359 & & \\
\hline rs 2303151 & HMGCR & $\mathrm{A} / \mathrm{G}$ & 5 & 74691207 & & \\
\hline rs 12916 & HMGCR & $\mathrm{C} / \mathrm{T}$ & 5 & 74692295 & & \\
\hline rs2544040 & VDR & $\mathrm{A} / \mathrm{G}$ & 12 & 46509213 & 4.42 & 79.60 \\
\hline rs|l 608702 & VDR & $\mathrm{A} / \mathrm{T}$ & 12 & 46515035 & & \\
\hline rs7968585 & VDR & $\mathrm{C} / \mathrm{T}$ & 12 & 46518360 & & \\
\hline rs9729 & VDR & $\mathrm{A} / \mathrm{C}$ & 12 & 46522890 & & \\
\hline rs73।236 (Taql) & VDR & $\mathrm{C} / \mathrm{T}$ & 12 & 46525024 & & \\
\hline rs7975232 (Apal) & VDR & $\mathrm{A} / \mathrm{C}$ & 12 & 46525104 & & \\
\hline rs I5444I0 (Bsml) & VDR & $\mathrm{A} / \mathrm{G}$ & 12 & 46526102 & & \\
\hline rs2248098 & VDR & $\mathrm{C} / \mathrm{T}$ & 12 & 46539623 & & \\
\hline rs2239179 & VDR & $\mathrm{A} / \mathrm{G}$ & 12 & 46544033 & & \\
\hline rs88644I & VDR & $\mathrm{C} / \mathrm{T}$ & 12 & 46549231 & & \\
\hline rs I07358I0 (Fokl) & VDR & $A / G$ & 12 & 46559162 & & \\
\hline rs2254210 & VDR & $A / G$ & 12 & 46559981 & & \\
\hline rs2853564 & VDR & $\mathrm{C} / \mathrm{T}$ & 12 & 46564754 & & \\
\hline rs2853559 & VDR & $\mathrm{C} / \mathrm{T}$ & 12 & 46569072 & & \\
\hline rs3890734 & VDR & $\mathrm{A} / \mathrm{G}$ & 12 & 46575622 & & \\
\hline rs 10783219 & VDR & $\mathrm{A} / \mathrm{T}$ & 12 & 46581755 & & \\
\hline rs 4516035 & VDR & $\mathrm{C} / \mathrm{T}$ & 12 & 46586093 & & \\
\hline rsII 568820 (CDX-2) & VDR & $\mathrm{A} / \mathrm{G}$ & 12 & 46588812 & & \\
\hline rs3764261 & CETP & $\mathrm{G} / \mathrm{T}$ & 16 & 55550825 & 5.10 & 30.61 \\
\hline rs7।I752 & CETP & $\mathrm{A} / \mathrm{G}$ & 16 & 55553712 & & \\
\hline rs 1532624 & CETP & $\mathrm{G} / \mathrm{T}$ & 16 & 55562980 & & \\
\hline rs5882 & CETP & $\mathrm{A} / \mathrm{G}$ & 16 & 55573593 & & \\
\hline rs2303790 & CETP & $\mathrm{A} / \mathrm{G}$ & 16 & 55574793 & & \\
\hline rs 289747 & CETP & $\mathrm{A} / \mathrm{G}$ & 16 & $5558 \mid 439$ & & \\
\hline
\end{tabular}

SNPs are identified by their rs number, gene, alleles, chromosome and position according to HapMap release \#23a (NCBI build 36, dbSNP bI26), average distance between markers and gene extension in $\mathrm{Kb}$.

\section{TagSNP transferability and LD analysis}

The tagSNP transferability study was conducted using the Stampa algorithm [34] implemented on the Gevalt package [35]. This algorithm aims to maximize the expected accuracy of predicting untyped SNPs based on genotype data of the tagSNPs [34]. To conduct this study, first the variability prediction accuracy for each gene was assessed to calculate the coverage of the HapMap phase II data in relation to the total number of available SNPs in each region: number of common SNPs with minor allele frequency (MAF) > 0.05; number of SNPs required to capture $100 \%$ of SNP prediction; maximum prediction using the same number of SNPs as in the study; and the prediction for the selected set of SNPs. Then, the set of SNPs selected with average distances of $5 \mathrm{~Kb}$ had their variability prediction calculated based on two until the maximum number of tagSNPs for all five samples. Finally, the relative loss of variability prediction (in percentage points; $\mathrm{pp}$ ) was calculated by subtracting the variability prediction of tagSNPs selected for BRA from the relative prediction obtained when using the tagSNPs selected for each of the HapMap populations and the pooled sample in the Brazilian group.

Measures of linkage disequilibrium (LD) between pairs of SNP loci $\left(D^{\prime}\right.$ and $r^{2}$ ) were calculated by the Gerbil algorithm [36], implemented in Gevalt, using the standard maximum-likelihood and expectation-maximization algorithm methods. Only the SNPs accounted for in all five populations were evaluated. A pairwise population LD analysis was carried out using a Spearman's correlation coefficient. 


\section{Results Variability coverage of HapMap}

The characteristics of each gene region varied according to the number of SNPs available in phase II of HapMap (Table 2). The most critical difference was the SNP density at each region, which varied from approximately 0.80 to 3.30 SNPs per Kb, though it was conserved among populations (Table 2). The overall average variability of the selected SNPs was $89.55 \%$ representing 6.7 percentage points (pp) of loss from the maximum of variability using the same number of tagSNPs selected by the algorithm. Each population presented a different loss of prediction per gene. The population average that presented the highest loss of prediction was CHB+JPT with $8.11 \mathrm{pp}$, followed by CEU (7.33 pp) and YRI (4.68 pp). The gene that had the highest loss of prediction on average was the PTPN22 (9.40 pp), followed by CETP (7.33 pp), HMGCR (5.21 pp) and VDR (4.87 pp).

The prediction power of the evaluated SNPs differed among the genes. Overall, the Brazilian sample displayed a lower power of prediction when compared to HapMap and the pooled sample. The only exception occurred in the PTPN22 gene where CEU predictions were always lower than those for BRA (Figure 1). At the HMGCR gene, the prediction was, on average, 15.34 pp lower for BRA than the average for the other HapMap populations (Figure 1), while in other genes this difference was smaller (VDR 5.36 pp, PTPN22 3.32 pp and CETP 3.92 pp).

\section{TagSNP transferability analysis}

To evaluate the transferability of tagSNPs, the prediction of variability coverage in the BRA sample was calculated for the set of SNPs in each of the HapMap populations and the POOL sample. The relative loss was calculated by subtracting the prediction coverage using the HapMap tagSNPs from the prediction coverage of those tagSNPs in BRA. This simple calculation gives an idea of the prediction loss as opposed to a true prediction in an admixed sample, since the SNPs evaluated are presented for all population data. The average prediction loss varied among genes and among populations (Table 3). Considering only the HapMap samples, $\mathrm{CHB}+\mathrm{JPT}$ had the lowest prediction loss on average, followed by CEU and YRI, but in general, the pooled HapMap sample resulted in the lowest relative prediction losses (Table 3 ). When using only one population tagSNP as reference there can be substantial losses in some regions, for instance the VDR and PTPN22 genes when using YRI tagSNP, while in other cases there can be minor loss, as observed in the HMGCR gene when using YRI tagSNPs. It was observed that the loss of prediction tends to increase as the number of tagSNP increases, but decreases or becomes stable with the last groups of tags (data not shown).

\section{Pairwise LD analysis}

A comparison of pairwise LD correlation analysis was assessed between the Brazilian sample, the HapMap and the pooled data. When each region was examined individually, LD analysis between BRA and the other samples did not find significant values for $D^{\prime}$ measurements (data not shown), except for at the VDR locus, for which Spearman's correlation coefficients (rho) were 0.067 for YRI, 0.401 for $\mathrm{CHB}+\mathrm{JPT}, 0.737$ for CEU and 0.632 for POOL, whereas for LD $r^{2}$ a higher correlation was found for the POOL data, except for at the VDR locus (Table 4). When all pairs of SNPs were compared between BRA and the other populations the correlation coefficients followed

Table 2: SNP prediction Coverage for HapMap population samples

\begin{tabular}{|c|c|c|c|c|c|c|c|}
\hline Population & Gene & Total SNPs & Density (SNP/Kb) & Common SNPs & $\mathrm{n}$ to $100 \%$ prediction & $\begin{array}{l}\text { Prediction of selected } \\
\text { SNPs (\%) }\end{array}$ & Max. Prediction (\%) \\
\hline $\mathrm{CHB}+\mathrm{JPT}$ & PTPN22 & 30 & 0.86 & $21(70 \%)$ & 14 & 87.15 & 99.59 \\
\hline CEU & & 28 & 0.80 & $21(75 \%)$ & 17 & 88.00 & 98.50 \\
\hline YRI & & 29 & 0.83 & $17(59 \%)$ & 12 & 93.91 & 99.17 \\
\hline $\mathrm{CHB}+\mathrm{JPT}$ & HMGCR & 23 & 0.81 & $20(87 \%)$ & 19 & 90.17 & 98.12 \\
\hline CEU & & 24 & 0.84 & 22 (92\%) & 21 & 93.56 & 97.50 \\
\hline YRI & & 23 & 0.81 & $17(74 \%)$ & 16 & 94.33 & 98.08 \\
\hline $\mathrm{CHB}+\mathrm{JPT}$ & VDR & 162 & 2.04 & $84(52 \%)$ & 73 & 92.91 & 98.00 \\
\hline CEU & & 161 & 2.02 & 94 (58\%) & 79 & 92.12 & 96.67 \\
\hline YRI & & 159 & 2.00 & $107(67 \%)$ & 101 & 88.20 & 93.17 \\
\hline $\mathrm{CHB}+\mathrm{JPT}$ & CETP & 102 & 3.33 & $55(54 \%)$ & 51 & 86.18 & 93.13 \\
\hline CEU & & 101 & 3.30 & $48(48 \%)$ & 40 & 82.74 & 93.07 \\
\hline YRI & & 102 & 3.33 & $69(68 \%)$ & 61 & 85.33 & 90.05 \\
\hline
\end{tabular}

Coverage is based on a total number of SNPs, region density measured by SNP/Kb, number of common SNPs (MAF <0.05), number of common SNPs to reach $100 \%$ of prediction, prediction of the selected SNPs and the maximum prediction using the same number of SNPs. 

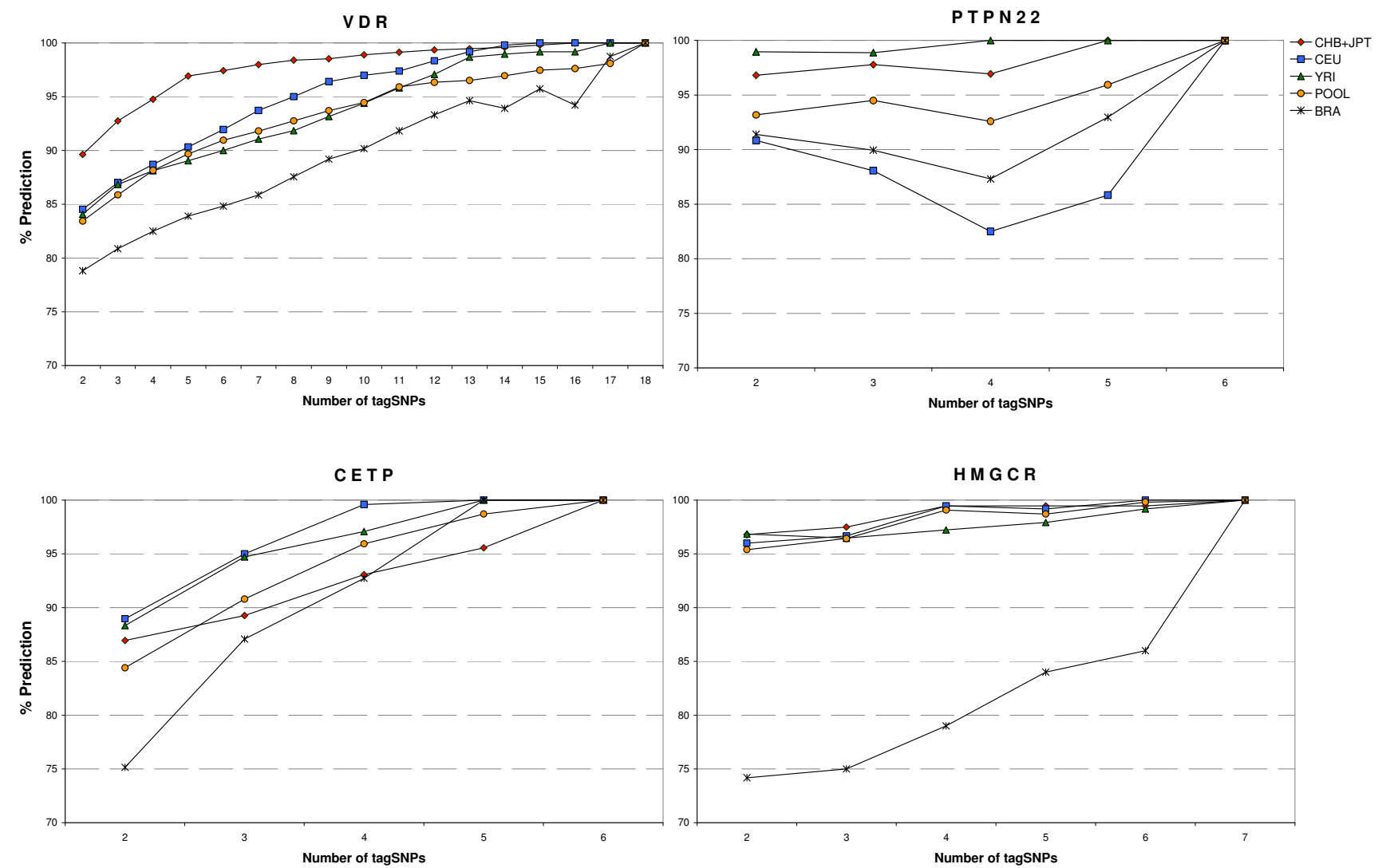

Figure I

Variability prediction in each gene. Percentage of prediction is described in each population sample from the minimum of two to the maximum number of SNPs studied in each loci (VDR, PTPN22, CETP and HMGCR).

the same order using either $D^{\prime}$ or $r^{2}$ (CEU, POOL, $\mathrm{CHB}+\mathrm{JPT}$ ), and LD $r^{2}$ correlation coefficients (rho) were slightly higher when compared to $D^{\prime}$ measurements.

\section{Discussion}

The success of a genetic association study is strongly affected by marker selection for a specific population. With regard to admixed populations this criterion is of fundamental concern due to the risk of spurious associa-

Table 3: Loss of SNP prediction coverage in BRA using HapMap tagSNPs

\begin{tabular}{llllll}
\hline TagSNP set & PTPN22 & HMGCR & VDR & CETP & A.V. \pm S.D. \\
\hline CHB+JPT & 3.035 & 4.936 & 6.448 & 0.253 & $3.668 \pm 2.67 I$ \\
CEU & 7.995 & 3.600 & 4.211 & 2.120 & $4.48 I \pm 2.50 I$ \\
YRI & 7.608 & 2.222 & 12.078 & 3.580 & $6.372 \pm 4.438$ \\
POOL & 2.940 & 4.390 & 4.221 & 2.198 & $3.437 \pm 1.050$
\end{tabular}

Loss of SNP prediction coverage is given by percentage point difference between the SNP prediction defined in BRA and the prediction in BRA using the set of tagSNPs selected for the HapMap populations. Last column displays average values \pm standard deviation. tions in the case of inefficient choice. The HapMap Consortium provided solutions for most cases by making available millions of markers genome-wide that were genotyped in each of the continental populations, although it did not address how markers selected in one or more HapMap samples will perform in studies with other populations [8]. To date, several studies have evaluated tagSNPs portability in a range of worldwide populations, but none has assessed a heterogeneous admixed population. The present study indicates that tagSNP sets from HapMap

Table 4: Spearman's correlation coefficient (rho)

\begin{tabular}{lllll}
\hline$r^{2}$ & CHB+JPT & CEU & YRI & POOL \\
\hline PTPN22 & 0.697 & 0.813 & 0.543 & 0.949 \\
HMGCR & 0.853 & 0.816 & 0.862 & 0.902 \\
VDR & 0.312 & 0.742 & 0.321 & 0.639 \\
CETP & 0.821 & 0.785 & $-0.018^{*}$ & 0.912 \\
overall & 0.491 & 0.782 & 0.431 & 0.719 \\
\hline
\end{tabular}

Correlation of LD measures $\left(r^{2}\right)$ for all SNP pairs between BRA and HapMap populations. * $p$-value not significant, all others were statistically significant $(p<0.05)$. 
population can be portable to admixed populations to a reasonable degree, however the results can also be uncertain and inaccurate if applied improperly. It also demonstrates the necessity for understanding the patterns of physical (gene extension and SNP density) and genetic (LD patterns) differences in every genomic region prior to determining the tagSNPs to be used, in order to make a reasonable prediction for untyped markers.

Measures of LD and SNP density vary across the genome and can be critical points when selecting a set of tagSNPs. A study by Tantoso and colleagues [37] showed that SNPs can be transferred from HapMap to other populations of the same ethnic and continental origin. Even so, tagSNP coverage increases along with the SNP density due to the high LD in European and the Asian populations. Hence, coverage of many untyped variants, especially the rare ones (MAF <0.05), drops from 50\% to 30\% depending on the population used [37]. Another study [15] showed that the SNP density has a major effect on tag selection, proposing denser sets (i.e., one SNP every $1.3 \mathrm{~kb}$ ) to improve the tagSNP performance. In the present study the SNPs were selected with SNP density that was approximately equal in the four regions studied (one SNP every $5 \mathrm{~kb}$ ), to reduce or eliminate such an effect. Using the same genotyped SNP density at two regions with physically different densities CETP (30 kb and $3.3 \mathrm{SNP} / \mathrm{kb}$ ) and HMGCR (28 $\mathrm{kb}$ and $0.8 \mathrm{SNP} / \mathrm{kb}$ ) demonstrates that either maximum or minimum prediction among regions and within the population provided no more than 10 percentage points of loss in prediction (Table 2). Though, the fact that the prediction becomes stable or decreases as the number of tagSNPs increases is evidence that SNP density can be a critical point in tagSNP selection in larger genome-wide sets $[15,37]$, as well as in low-throughput region analysis, emphasizing that for an admixed population it is necessary to use, in a reduced panel, as many SNPs as possible.

The SNP prediction and tagSNP transferability are also dependent on the linkage disequilibrium patterns and hence in admixed populations they can be influenced both by the demographic events and by genetic factors. Generally, tagSNP sets selected for similar populations with similar haplotype block structures have better performance but differ if the block structures and boundaries also differ [6,9-12,38]. For instance, CEU tags are useful for populations with European ancestry and tagSNPs selected for YRI perform well in Sub-Saharan Africans, but require larger genotype densities due to lower LD among markers [11,12,37].

The linkage disequilibrium measures could be evidence leading to the belief that one could use tagSNPs directly transferred from CEU to BRA without great loss of variability, since the greatest ancestral contribution in the Bra- zilian sample is European [24,25,30,31]. Considering all SNP pairs in the current dataset the pairwise LD had the highest correlation between BRA and CEU, followed by POOL, CHB+JPT and YRI, which had the lowest average LD and was less correlated. However when genes were analyzed individually, except for the VDR gene, the POOL data had the highest correlation compared to the other populations.

Although using tagSNPs directly form CEU worked with great efficiency in some cases, as in the case of VDR gene, in others this type of selection provided greater loss of variability, as in the specific case of the PTPN22 gene, reinforcing the idea that each genomic region will perform according to gene and population structure [6]. Linkage disequilibrium arising from the recent admixture of genetically distinct populations can be categorized as a genome-wide effect and thus selecting markers from representative parental populations offers analytical risks due to the fact that in some genomic regions, particularly those with high LD, ancestral haplotype-block structures at the individual level are not always eliminated by recent admixture.

Population stratification along the Latin American populations varies extensively as consequence of their history of immigration and colonization over the last five centuries. In Brazil there is a major contribution from the European ancestry followed by African and Amerindian $[24,25,30,31]$. In the present data the pooled sample tagSNP performance had a relative loss of prediction smaller than any other population sample. Although the relative loss of prediction among $\mathrm{CHB}+\mathrm{JPT}$ and POOL were very close, the fact that standard deviation in the pooled sample was lower demonstrated that, in a study with multiple gene analysis, it can be a safe alternative to choose tagSNPs from the pooled samples, because different LD patterns at different genes can have different SNP coverage depending on each of the HapMap populations [6].

In other Latin-American populations, such as those from Mexico or Argentina, the contributions of the Amerindian proportion at population level are usually higher than in Brazil, and African ancestry is higher in Caribbean populations than in any other [39-41]. Such population structure difference should be considered when applying a tagSNP selection method depending on each specific case of admixture. It is possible that for Mexicans or Argentineans a combination of the CEU, CHB and JPT HapMap samples would perform better than the whole HapMap pool, as was the case for South Asian populations such as the Indian population [6] and Hazara, Kalash and Uygur populations [11]. The combinations of HapMap panels were also effective at representing other populations, such as the Philippines [42], for which CHB samples and the 
combined $\mathrm{CHB}+\mathrm{JPT}$ samples were most transferable to Cebu Filipino samples, indicating that different pools of HapMap panels should be tested and used as an alternative in many situations.

However, it is noteworthy that the SNP coverage in HapMap is not complete and tagging strategies critically depend on the investigation of other population polymorphisms [18]. The project is now overcoming the representative world-wide population issue with the Phase III release, which includes Amerindian and Mexican ancestral populations among others. This will certainly improve the methods of tagSNP selection for admixed populations but a comprehensive study using highthroughput genome-wide SNPs in assorted admixed populations will be required to reduce confounding effects caused by population stratification and to enhance the tagSNP performance. Identification, re-sequencing, and genotyping of large-scale and high-throughput SNP data were beyond the scope of this study. Further analysis will be necessary to assess if such techniques will attain the same level of efficiency in other admixed populations in which a history of admixture processes differs from the Brazilian sample, known for being recent and continuous, as opposed to populations which have undergone well defined time limited admixture processes in the past.

\section{Conclusion}

The pooled HapMap sample provided the minimum loss of prediction in admixed population and therefore, combined with the SNP selection spaced at most every $5.0 \mathrm{~kb}$ may represent an efficient alternative. The present findings will be useful for the future design and analysis of genetic studies using other admixed populations, suggesting that on such occasions the selection of markers should not be generalized according to the tagSNPs of one or other current HapMap populations due to genetic and demographic effects.

\section{Competing interests}

The authors declare that they have no competing interests.

\section{Authors' contributions}

TCL performed molecular analysis of PTPN22 and VDR genes, interpreted the data and drafted the manuscript. BSA designed the study, performed molecular analysis of CETP and HMGCR genes, interpreted the data and participated in manuscript drafting. RWP conceived, coordinated and designed the study. The authors read and approved the final manuscript.

\section{Acknowledgements}

This work was supported by Coordenação de Aperfeiçoamento de Pessoal de Nível Superior (CAPES), Conselho Nacional de Desenvolvimento Científico e Tecnológico (CNPq), and Universidade Católica de Brasília (PRPGP-UCB). TCL and BSA were supported by a CAPES Master's schol- arship. We thank Dr. Dario Grattapaglia for the ABI3I00 sharing and providing the Brazilian samples and Rodrigo $G$ Vieira for extensive work of genotyping and estimating the individual ancestry of the Brazilian samples. We are grateful to Robert Pogue for English version review of the final manuscript.

\section{References}

I. Risch N, Merikangas K: The future of genetic studies of complex human diseases. Science 1996, 273:1516.

2. Johnson GC, Esposito L, Barratt BJ, Smith AN, Heward J, Di Genova G, Ueda H, Cordell HJ, Eaves IA, Dudbridge F, et al:: Haplotype tagging for the identification of common disease genes. Nat Genet 200I, 29:233-237.

3. Sachidanandam R, Weissman D, Schmidt SC, Kakol JM, Stein LD, Marth G, Sherry S, Mullikin JC, Mortimore BJ, Willey DL, et al.: A map of human genome sequence variation containing $\mathbf{I . 4 2}$ million single nucleotide polymorphisms. Nature 200I, 409:928-933.

4. Carlson CS, Eberle MA, Rieder MJ, Yi Q, Kruglyak L, Nickerson DA: Selecting a maximally informative set of single-nucleotide polymorphisms for association analyses using linkage disequilibrium. Am J Hum Genet 2004, 74: 106- 20.

5. Ke X, Cardon LR: Efficient selective screening of haplotype tag SNPs. Bioinformatics 2003, 19:287-288.

6. Xing J, Witherspoon DJ, Watkins WS, Zhang Y, Tolpinrud W, Jorde LB: HapMap tagSNP transferability in multiple populations: general guidelines. Genomics 2008, 92:4I-5I.

7. Andrawiss M: First phase of HapMap project already helping drug discovery. Nat Rev Drug Discov 2005, 4:947.

8. The International HapMap Consortium: A haplotype map of the human genome. Nature 2005, 437:1299-1320.

9. Gonzalez-Neira A, Ke X, Lao O, Calafell F, Navarro A, Comas D, Cann H, Bumpstead S, Ghori J, Hunt S, et al:: The portability of tagSNPs across populations: a worldwide survey. Genome Res 2006, 16:323-330.

10. Sawyer SL, Mukherjee N, Pakstis AJ, Feuk L, Kidd JR, Brookes AJ, Kidd KK: Linkage disequilibrium patterns vary substantially among populations. Eur J Hum Genet 2005, 13:677-686.

II. Conrad DF, Jakobsson M, Coop G, Wen X, Wall JD, Rosenberg NA, Pritchard JK: A worldwide survey of haplotype variation and linkage disequilibrium in the human genome. Nat Genet 2006, 38: $125 \mid-1260$.

12. de Bakker PI, Burtt NP, Graham RR, Guiducci C, Yelensky R, Drake JA, Bersaglieri T, Penney KL, Butler J, Young S, et al.: Transferability of tag SNPs in genetic association studies in multiple populations. Nat Genet 2006, 38: 1298-1303.

13. Gu S, Pakstis AJ, Li H, Speed WC, Kidd JR, Kidd KK: Significant variation in haplotype block structure but conservation in tagSNP patterns among global populations. Eur J Hum Genet 2007, I5:302-3/2.

14. Huang W, He Y, Wang H, Wang Y, Liu Y, Chu X, Xu L, Shen Y, Xiong $X$, Li H, et al.: Linkage disequilibrium sharing and haplotypetagged SNP portability between populations. Proc Natl Acad Sci USA 2006, 103:1418-1421.

15. Montpetit A, Nelis M, Laflamme P, Magi R, Ke X, Remm M, Cardon L, Hudson TJ, Metspalu A: An evaluation of the performance of tag SNPs derived from HapMap in a Caucasian population. PLoS Genet 2006, 2:e27.

16. Service S, Sabatti C, Freimer N: Tag SNPs chosen from HapMap perform well in several population isolates. Genet Epidemiol 2007, $31: 189-194$.

17. Willer CJ, Scott LJ, Bonnycastle LL, Jackson AU, Chines P, Pruim R, Bark CW, Tsai YY, Pugh EW, Doheny KF, et al:: Tag SNP selection for Finnish individuals based on the CEPH Utah HapMap database. Genet Epidemiol 2006, 30: 180-190.

18. Barrett JC, Cardon LR: Evaluating coverage of genome-wide association studies. Nat Genet 2006, 38:659-662.

19. Xu Z, Kaplan NL, Taylor JA: Tag SNP selection for candidate gene association studies using HapMap and gene resequencing data. Eur J Hum Genet 2007, I 5: $1063-1070$.

20. Choudhry S, Coyle NE, Tang H, Salari K, Lind D, Clark SL, Tsai HJ, Naqvi M, Phong A, Ung N, et al:: Population stratification confounds genetic association studies among Latinos. Hum Genet 2006, I | 8:652-664 
21. Hoggart CJ, Parra EJ, Shriver MD, Bonilla C, Kittles RA, Clayton DG, McKeigue PM: Control of confounding of genetic associations in stratified populations. Am J Hum Genet 2003, 72: I492-1504.

22. Ziv E, Burchard EG: Human population structure and genetic association studies. Pharmacogenomics 2003, 4:43I-44I.

23. Patterson N, Hattangadi N, Lane B, Lohmueller KE, Hafler DA, Oksenberg JR, Hauser SL, Smith MW, OBrien SJ, Altshuler D, et al.: Methods for high-density admixture mapping of disease genes. Am J Hum Genet 2004, 74:979-1000.

24. Callegari-Jacques SM, Grattapaglia D, Salzano FM, Salamoni SP, Crossetti SG, Ferreira ME, Hutz MH: Historical genetics: spatiotemporal analysis of the formation of the Brazilian population. Am J Hum Biol 2003, I 5:824-834.

25. Salzano FM: Interethnic variability and admixture in Latin America social implications. Rev Biol Trop 2004, 52:405-4I5.

26. Sans M: Admixture studies in Latin America: from the 20th to the 2 I st century. Hum Biol 2000, 72:155-177.

27. McKeigue PM: Prospects for admixture mapping of complex traits. Am J Hum Genet 2005, 76: I-7.

28. Terwilliger JD, Hiekkalinna T: An utter refutation of the "Fundamental Theorem of the HapMap". Eur J Hum Genet 2006, 1 4:426-437.

29. Xu S, Huang W, Wang H, He Y, Wang Y, Qian J, Xiong M, Jin L: Dissecting linkage disequilibrium in African-American genomes: roles of markers and individuals. Mol Biol Evol 2007, 24:2049-2058.

30. Lins TC: [Impact of admixture on the performance of HapMap data in Brazilian population assessed in PTPN22 and VDR genes]. Universidade Católica de Brasília, Dissertation Thesis; 2007.

31. Lins TC, Vieira RG, Abreu BS, Grattapaglia D, Pereira RW: Genetic composition of Brazilian population samples based on a set of twenty eight ancestry informative SNPs. Am J Hum Biol 2009. Epub:DOI 10.1002/ajhb.20976

32. Phillips MS, Lawrence R, Sachidanandam R, Morris AP, Balding DJ, Donaldson MA, Studebaker JF, Ankener WM, Alfisi SV, Kuo FS, et al.: Chromosome-wide distribution of haplotype blocks and the role of recombination hot spots. Nat Genet 2003, 33:382-387.

33. Lins TC, Nogueira LR, Lima RM, Gentil P, Oliveira RJ, Pereira RW: A multiplex single-base extension protocol for genotyping Cdx2, Fokl, Bsml, Apal, and Taql polymorphisms of the vitamin D receptor gene. Genet Mol Res 2007, 6:3।6-324.

34. Halperin E, Kimmel G, Shamir R: Tag SNP selection in genotype data for maximizing SNP prediction accuracy. Bioinformatics 2005, 2 I(Suppl I):il 95-203.

35. Davidovich O, Kimmel G, Shamir R: GEVALT: an integrated software tool for genotype analysis. BMC Bioinformatics 2007, 8:36.

36. Kimmel G, Shamir R: GERBIL: Genotype resolution and block identification using likelihood. Proc Natl Acad Sci USA 2005, 102: 158-162.

37. Tantoso E, Yang Y, Li KB: How well do HapMap SNPs capture the untyped SNPs? BMC Genomics 2006, 7:238.

38. Liu N, Sawyer SL, Mukherjee N, Pakstis AJ, Kidd JR, Kidd KK, Brookes AJ, Zhao H: Haplotype block structures show significant variation among populations. Genet Epidemiol 2004, 27:385-400.

39. Benn-Torres J, Bonilla C, Robbins CM, Waterman L, Moses TY, Hernandez W, Santos ER, Bennett F, Aiken W, Tullock T, et al.: Admixture and population stratification in African Caribbean populations. Ann Hum Genet 2008, 72:90-98.

40. Martinez-Marignac VL, Valladares A, Cameron E, Chan A, Perera A, Globus-Goldberg R, Wacher N, Kumate J, McKeigue P, O'Donnell D, et al.: Admixture in Mexico City: implications for admixture mapping of type 2 diabetes genetic risk factors. Hum Genet 2007, I 20:807-8|9.

41. Seldin MF, Tian C, Shigeta R, Scherbarth HR, Silva G, Belmont JW, Kittles R, Gamron S, Allevi A, Palatnik SA, et al.: Argentine population genetic structure: large variance in Amerindian contribution. Am J Phys Anthropol 2007, I32:455-462.

42. Marvelle AF, Lange LA, Qin L, Wang Y, Lange EM, Adair LS, Mohlke $\mathrm{KL}$ : Comparison of ENCODE region SNPs between Cebu Filipino and Asian HapMap samples. J Hum Genet 2007, 52:729-737.
Publish with Biomed Central and every scientist can read your work free of charge

"BioMed Central will be the most significant development for disseminating the results of biomedical research in our lifetime. "

Sir Paul Nurse, Cancer Research UK

Your research papers will be:

- available free of charge to the entire biomedical community

- peer reviewed and published immediately upon acceptance

- cited in PubMed and archived on PubMed Central

- yours - you keep the copyright
BioMedcentral 